\title{
Deposition of NiO Thin Films by Sol-Gel Spin Coating: Effect of Annealing Temperature on Structural, Optical and Electrical Properties
}

\author{
N. Parimon, M. H. Mamat, A. S. Zoolfakar, M. F. Malek, I. B. Shameem Banu, N. Vasimalai, and \\ M. Rusop
}

\begin{abstract}
Nickel oxide (NiO) thin films were deposited by solgel spin coating approach and annealed at different temperatures of $300{ }^{\circ} \mathrm{C}, 400{ }^{\circ} \mathrm{C}$, and $500{ }^{\circ} \mathrm{C}$. Herein, the influence of the heattreated process on $\mathrm{NiO}$ thin films to the morphological, structural, optical, and electrical properties were investigated. The field emission scanning electron microscopy reveals that the grain morphology is clearly visible with a random orientation at the highest temperature of $500{ }^{\circ} \mathrm{C}$. Subsequently, the grains are gradually blurred and not clearly seen with the decreases of the annealing temperature. The $\mathrm{X}$-ray diffraction pattern shows that a strong intensity peak of $\mathrm{NiO}$ is observed for the sample at an annealing temperature of $500{ }^{\circ} \mathrm{C}$ indicating the enhancement of the film crystallinity is at the highest temperature. The average crystallite sizes of $\mathrm{NiO}$ thin films were calculated using the Scherrer formula and yielded various sizes with a maximum value of $19 \mathrm{~nm}$ for $500{ }^{\circ} \mathrm{C}$-annealed sample. The bandgap energies of the samples were estimated from the Tauc's plot to be in the values between 4.08 to $4.11 \mathrm{eV}$. The electrical properties indicate that the resistance and the resistivity of $\mathrm{NiO}$ thin films decrease as the annealing temperature increased. From the results, it shows the potential of these $\mathrm{NiO}$ thin films for the application of sensing measurement.
\end{abstract}

Index Terms-NiO thin films, sol-gel spin coating, annealing temperature, structural properties, optical properties, electrical properties

\section{INTRODUCTION}

$I^{2}$ $\mathrm{N}$ a group of p-type metal oxides, nickel oxide $(\mathrm{NiO})$ is one 1 of the most investigated semiconductors with a wide bandgap $(3.6-4.0 \mathrm{eV})$ between the valence and conduction bands. NiO has recently gained prodigious attention because of its remarkable structural, optical, and electrical properties, as well as its good chemical stability [1]. These excellent

This manuscript is submitted on 19 December 2019 and accepted on 26 March 2020.

N. Parimon, M. H. Mamat, A. S. Zoolfakar, and M. Rusop are from NANO-ElecTronic Centre (NET), Faculty of Electrical Engineering, Universiti Teknologi MARA (UiTM), 40450 Shah Alam, Selangor, Malaysia (e-mail:mhmamat@uitm.edu.my)

M. F. Malek is from NANO-SciTech Centre (NST), Institute of Science (IOS), Universiti Teknologi MARA (UiTM), 40450 Shah Alam, Selangor, Malaysia.

I. B. Shameem Banu and N. Vasimalai are from School of Physical and Chemical Sciences, B.S. Abdur Rahman Crescent Institute of Science \& Technology, Vandalur, Chennai 600 048, India.

$1985-5389 /(C) 2021$ The Authors. Published by UiTM Press. This is an open access article under the CC BY-NC-ND license (http://creativecommons.org/ 28 licenses/by-nc-nd/4.0/). properties enable $\mathrm{NiO}$ to be a promising material for use in numerous applications such as gas sensors, photovoltaic solar cells, catalysts, and electrochemical devices [2-4] due to its wide and tunable optical bandgap [5].

Many studies have been conducted and showed that $\mathrm{NiO}$ properties can be enhanced by applying the heat-treatment process. It involves annealing process that generally leads to the complete formation of the oxide in the deposited material. According to Cayir [2], the structural, morphological, and optical properties of $\mathrm{NiO}$ thin films could be developed with the process of the annealing. From the result, a dominant (111) peak of $\mathrm{NiO}$ showed enhancement when the annealing temperature is increased. Furthermore, the grain size increased and bandgap values decreased with the increase of the annealing temperature. Akinkuade et al. [5] reported the effects of thermal treatment on structural, optical, and electrical properties of $\mathrm{NiO}$ thin films. They also mentioned the crystallinity of the films will get better and crystallite size increased if the annealing temperature is increased which causes the optical bandgap of the films to decrease. The resistivity of the films from 400 to $500{ }^{\circ} \mathrm{C}$-annealed was also seen to increase due to the increase in grain size. In another investigation, Yang et al. [3] have reported that the annealing treatment and the film thickness can influence the surface morphology and structural properties of the $\mathrm{NiO}$ films.

Many physical and chemical techniques have been employed in the synthesis of $\mathrm{NiO}$ thin films such as radio frequency magnetron sputtering $[1,3]$, spray pyrolysis [6], ebeam evaporation [7], pulsed laser deposition [8], and sol-gel $[4,9]$. Among these techniques, the sol-gel spin-coating is a viable approach to be used as a thin film-forming medium because of its distinctive advantages. It could produce a homogeneous solution with the controlled composition and microstructure, which leads to high-quality films deposited as desired [5]. This method is rarely mentioned to discuss the effect of annealing temperature on structural, optical, and electrical properties. Besides, the $\mathrm{NiO}$ thin films deposited through the sol-gel spin-coating attracts the attention of many studies due to the simplistic and low-cost preparation method $[6,9]$. The NiO thin films could be deposited on crystalline substrates such as silicon ( $\mathrm{Si})$, magnesium oxide $(\mathrm{MgO})$, alumina $\left(\mathrm{Al}_{2} \mathrm{O}_{3}\right)$ substrates [8], and amorphous glasses. 
Therefore, in this study, a facile and effective sol-gel spin coating method in ambient conditions was employed to produce $\mathrm{NiO}$ thin films on the glass substrate. The films were heated at various annealing temperatures to investigate the physical and electrical properties of the thin films. The heattreated $\mathrm{NiO}$ thin films are expected to be useful in many applications, including several sensors such as humidity as evidenced by our previous work [10-12].

\section{EXPERIMENTAL DETAILS}

$\mathrm{NiO}$ thin films were prepared onto glass substrates (size: 2.5 $\mathrm{cm} \times 2.5 \mathrm{~cm}$ ) using the sol-gel spin coating approach at ambient conditions. Before the coating process, the glass substrates were cleaned in a hydrochloric acid solution and rinsed with deionized (DI) water. Next, the substrates were cleaned ultrasonically using solutions of acetone, ethanol, and DI water for 15 minutes each. Thereafter, the glass substrates were dried under nitrogen $\left(\mathrm{N}_{2}\right)$ gas flow using a gas blower. In this work, $0.8 \mathrm{M}$ nickel acetate (precursor) was dissolved in diethanolamine (stabilizer) and ethylene glycol monoethyl ether (solvent) to produce a precursor solution. The solution was stirred for 2 hours at room temperature and used for preparing the $\mathrm{NiO}$ thin films. Then, the solution was deposited directly on the top of the glass substrates using the spin coater at the deposition speed of $4000 \mathrm{rpm}$ for 1 minute. After deposition, the layer was dried at $250{ }^{\circ} \mathrm{C}$ for 5 minutes. The deposition and drying processes were repeated five times, which finally resulted in 5 layers. Likewise, we prepared three such thin films and finally, these were annealed at different temperatures of $300{ }^{\circ} \mathrm{C}, 400{ }^{\circ} \mathrm{C}$, and $500{ }^{\circ} \mathrm{C}$ for 2 hours.

The morphology structures were examined by a field emission scanning electron microscopy (FESEM, Zeiss Supra 40VP). The thickness of the sample was determined using a surface profiler (KLA-Tencor P-6). The crystallinities of the $\mathrm{NiO}$ thin films were investigated using X-ray diffraction (XRD, PANalytical X'Pert PRO). For optical properties, ultraviolet-visible (UV-vis) spectrophotometer (Jasco/V-670 $\mathrm{EX}$ ) was used to determine the percentage of transmittance and value of absorbance for the deposited $\mathrm{NiO}$ thin films. The electrical characteristics of the thin films were analyzed using a two-probe current-voltage (I-V) measurement system (model: Advantest R6243). Prior to this measurement, silver (Ag) contacts were deposited on the top of films as the electrode by a thermal evaporation system (Ulvac VPC 1100) with the thickness of the metal contact was fixed at $60 \mathrm{~nm}$.

\section{RESULTS AND DISCUSSION}

\section{A. Surface Morphology}

Fig. 1 (a), (b), and (c) depicts the FESEM images of the $\mathrm{NiO}$ thin films that were annealed at three temperatures of 300 ${ }^{\circ} \mathrm{C}, \quad 400{ }^{\circ} \mathrm{C}$, and $500{ }^{\circ} \mathrm{C}$, respectively. Overall, the surface morphology shows the homogeneous grains with high density and it can be seen that the grains are randomly oriented with uniform size on the surface. The grains gradually become prominent, precise, and separate as the annealing temperature increased. Agglomeration of the particle is observed clearly in Fig. 1 (c) for $\mathrm{NiO}$ film annealed at a high temperature of 500
${ }^{\circ} \mathrm{C}$. It can be observed more distinctly compared to the other samples. This result shows that the grain size and the quality of the crystals are strongly dependent on the annealing temperature [2]. The thickness of the films increases with increasing annealing temperature, which manifests itself through the surface profiling measurements. The thicknesses of the thin films were $37.5 \mathrm{~nm}, 45.7 \mathrm{~nm}$, and $56.2 \mathrm{~nm}$ for 300 ${ }^{\circ} \mathrm{C}$-, $400{ }^{\circ} \mathrm{C}$-, and $500{ }^{\circ} \mathrm{C}$-annealed, respectively.
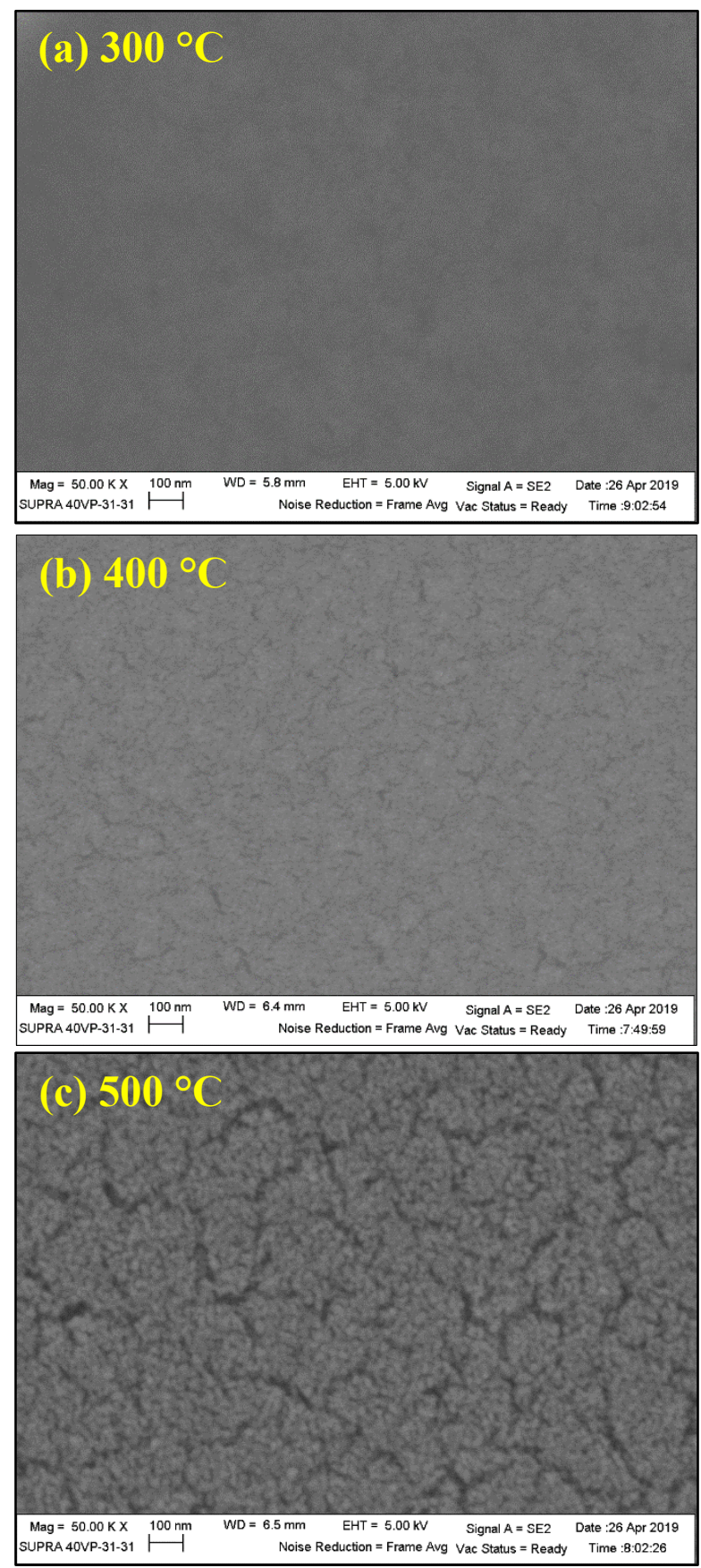

Fig. 1. Surface morphology of $\mathrm{NiO}$ thin films at annealing temperatures of (a) $300^{\circ} \mathrm{C}$, (b) $400^{\circ} \mathrm{C}$, and $500^{\circ} \mathrm{C}$.

\section{B. XRD Pattern}

The XRD patterns of $\mathrm{NiO}$ thin films at different annealing temperatures are shown in Fig. 2. The XRD peaks were recorded in the scanning range of $2 \theta$ between $20^{\circ}$ to $90^{\circ}$ to 
verify the characteristics of the polycrystalline $\mathrm{NiO}$ structure. The non-annealed $\mathrm{NiO}$ thin film is amorphous and therefore its XRD pattern is not shown in this manuscript. This condition is in agreement with the finding by Martínez-Gil et al [13]. It can be seen from Fig. 2 that the diffraction peak appears as early as $300{ }^{\circ} \mathrm{C}$ of the annealing temperature but with low intensity. The intensity of the diffraction peak increases as the annealing temperature increases. The observable peak at $300{ }^{\circ} \mathrm{C}$ could be attributed to the $0.8 \mathrm{M}$ precursor concentration used, which provides sufficient $\mathrm{NiO}$ molecules for lattice rearrangement of the crystallization even at a low temperature. As stated by Sahoo et al., the $0.5 \mathrm{M}$ precursor of nickel acetate can be crystallized to an oxide state at annealing temperature as low as $350{ }^{\circ} \mathrm{C}$ [14]. In another study, the $\mathrm{NiO}$ samples prepared using the SILAR method at various annealing temperatures showed polycrystalline structure including those without annealing process or asgrown samples [2]. The increment of the intensity as the annealing temperature increased is consistent with the result reported by Diha et al. [4]. Further, it shows the crystallinity quality of the film improves as the annealing temperature is increased. As stated by Ghougali et al. [15], the increase in the intensity of the diffraction peaks shows that the crystallinity of $\mathrm{NiO}$ is good. Therefore, the best crystalline quality of the film is achieved at the highest temperature of $500{ }^{\circ} \mathrm{C}$ as its XRD pattern exhibits dominant and stronger peaks compared to other samples. Five diffraction peaks were recorded in the XRD pattern of the $\mathrm{NiO}$ thin film at $500{ }^{\circ} \mathrm{C}$, which corresponding to the cubic $\beta$-NiO (JCPDS No. 047-1049). These peaks at $36.9^{\circ}, 43.0^{\circ}, 62.6^{\circ}, 75.2^{\circ}$, and $79.0^{\circ}$ were indexed to the (111), (200), (220), (311), and (222) crystal planes, respectively.

The polycrystalline and cubic $\beta-\mathrm{NiO}$ can also be indexed to both $300{ }^{\circ} \mathrm{C}$ - and $400{ }^{\circ} \mathrm{C}$-annealed films. The $300{ }^{\circ} \mathrm{C}$ - and 400 ${ }^{\circ} \mathrm{C}$-annealed $\mathrm{NiO}$ films exhibit dominant (200) peak at approximately $42.5^{\circ}$ and $43.0^{\circ}$, respectively. However, the 400 ${ }^{\circ} \mathrm{C}$-annealed sample shows a sharper peak than the $300{ }^{\circ} \mathrm{C}$ annealed sample. When the annealing temperature is increased from $300{ }^{\circ} \mathrm{C}$ to $500{ }^{\circ} \mathrm{C}$, the number of peaks is increased and the intensity of the peaks also increases. This condition indicates that the annealing temperature plays an important role in the crystallinity formation of $\mathrm{NiO}$ thin films.

Based on a full width at half maximum (FWHM) value, the crystallite size $(D)$ could be calculated from the XRD data. The variation of average crystallite sizes for the annealed $\mathrm{NiO}$ thin films calculated using Scherer formula (1) [10] is shown in Table I.

$$
D=\frac{0.94 \lambda}{\beta \cos \theta}
$$

where $\lambda$ is the $\mathrm{X}$-ray wavelength (1.54 $\AA$ ), $\beta$ is the FWHM (in $\mathrm{rad})$ of the peak, and $\theta$ is the diffraction angle. The $D$ value was acquired and calculated at (200) plane orientation as the plane is the most apparent peaks for all samples. The crystallite sizes were estimated to be $0.72 \mathrm{~nm}, 0.81 \mathrm{~nm}$, and 19 $\mathrm{nm}$ for $300{ }^{\circ} \mathrm{C}-$, $400{ }^{\circ} \mathrm{C}$-, and $500{ }^{\circ} \mathrm{C}$-annealed samples, respectively. From these values, it is clear that the average crystallite size increases as the annealing temperature is increased. This result is further reinforced from the report by Ruys et al. [15].

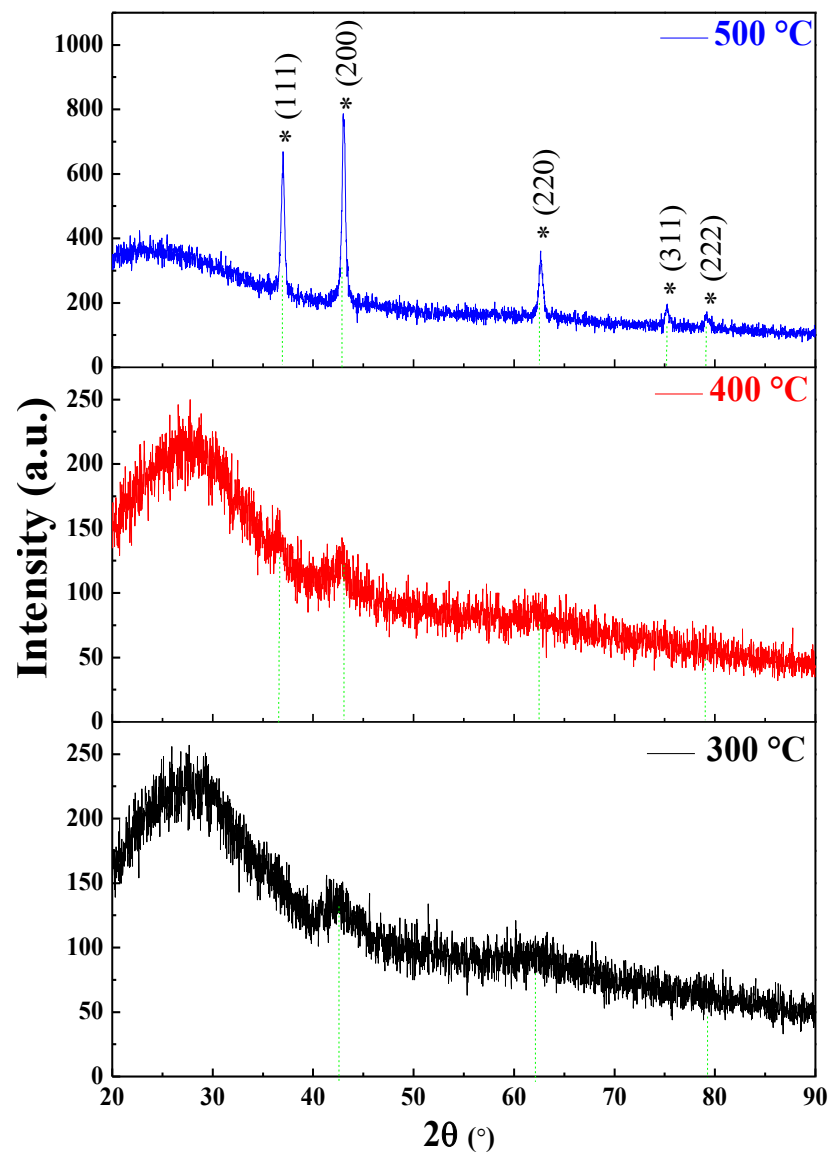

Fig. 2. The XRD patterns of $\mathrm{NiO}$ thin films at different annealing temperatures.

TABLE I

THE FWHM AND CRYSTALLITE SIZES OF NIO THIN FILMS AT DIFFERENT ANNEALING TEMPERATURES.

\begin{tabular}{cccc}
\hline $\begin{array}{c}\text { Sample } \\
\left({ }^{\circ} \mathbf{C}\right)\end{array}$ & $\begin{array}{c}\mathbf{2 \theta} \\
\left({ }^{\circ}\right)\end{array}$ & $\begin{array}{c}\text { FWHM, } \boldsymbol{\beta} \\
\left({ }^{\circ}\right)\end{array}$ & $\begin{array}{c}\text { Crystallite size, } \\
\boldsymbol{D} \\
(\mathbf{n m})\end{array}$ \\
\hline 300 & 42.353 & 12.303 & 0.70 \\
400 & 42.753 & 11.047 & 0.81 \\
500 & 43.035 & 0.469 & 19 \\
\hline
\end{tabular}

\section{Optical Properties}

The change in the crystallite size, which could be observed from the XRD analysis, may contribute to the changes in the optical properties [15]. As shown in Fig. 3, the transmittance spectra dependence on the wavelength ranging from 300 to $800 \mathrm{~nm}$ was measured. The front edge of the curves represents the intrinsic absorption of $\mathrm{NiO}$ [9]. It shows that the thin films exhibit high transparencies in the visible spectral region (400 $800 \mathrm{~nm}$ ). The average transmittance values in the visible region were estimated to be approximately $76 \%, 70 \%$, and 83 $\%$ for $300{ }^{\circ} \mathrm{C}-, 400{ }^{\circ} \mathrm{C}$-, and $500{ }^{\circ} \mathrm{C}$-annealed samples, respectively. It is observed that the transmittance percentage of $\mathrm{NiO}$ thin films exhibit a variation with the annealing 
temperature. This variation may be due to the variation of the grain sizes when annealed at different temperatures. The highest transmittance percentage was identified at $500{ }^{\circ} \mathrm{C}$ annealed sample, which probably due to the presence of voids between the grains that allow the light to penetrate easily.

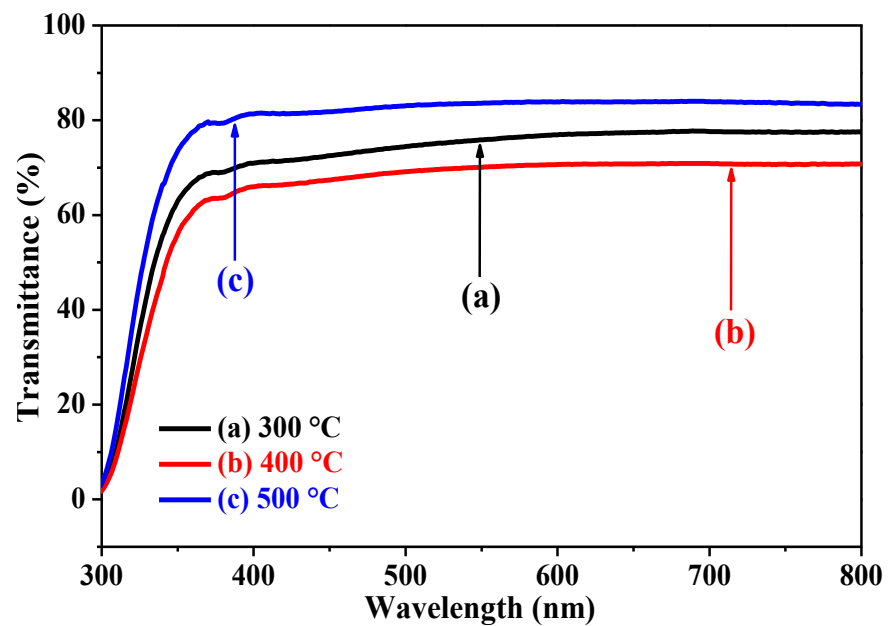

Fig. 3. Transmittance spectra of $\mathrm{NiO}$ thin films at different annealing temperatures.

Fig. 4 shows the absorption coefficient $(\alpha)$ spectra of $\mathrm{NiO}$ thin films annealed at various temperatures. As can be seen from all samples, the absorption values of photon energies are very low in the visible region $(400-800 \mathrm{~nm})$. However, the rapid increase in absorption occurs in the UV region at approximately $350 \mathrm{~nm}$. In detail, the absorption edges of 500 ${ }^{\circ} \mathrm{C}$-annealed is slightly shifted towards a shorter wavelength as compared to the samples that annealed in the lower annealing temperature. This may be due to the considerably large $\mathrm{NiO}$ crystalline size at an annealing temperature of $500^{\circ}$. In other situations, the absorption edges of $300{ }^{\circ} \mathrm{C}$ - and $400{ }^{\circ} \mathrm{C}$ annealed samples shifted to longer wavelengths. It can be said that the absorption coefficient is closely related to the percentage of transmission as well as the thin film thickness. This statement is substantiated by Lambert's law as expressed by the equation (2):

$$
\alpha=\frac{1}{t} \ln \left(\frac{1}{T}\right)
$$

where $\alpha, t$, and $T$ represent absorption coefficient, thickness, and transmittance of the thin film.

Based on the calculated absorption coefficient, the Tauc's plot was constructed and presented in Fig. 5 to determine the optical bandgap $\left(E_{\mathrm{g}}\right)$. The $E_{\mathrm{g}}$ can be determined from the extrapolated linear line of the graph by plotting $(\alpha h v)^{2}$ versus photon energy $(h v)$. The absorption coefficient $(\alpha)$, bandgap $\left(E_{\mathrm{g}}\right)$, and incident photon energy $(h v)$ are related by the expression (3):

$$
(\alpha h v)^{2}=B\left(h v-E_{g}\right)
$$

where $B$ represents a constant. The $E_{\mathrm{g}}$ values were estimated to be $4.08,4.09$, and $4.11 \mathrm{eV}$ for the $300{ }^{\circ} \mathrm{C}-, 400{ }^{\circ} \mathrm{C}$-, and 500 ${ }^{\circ} \mathrm{C}$-annealed samples, respectively.

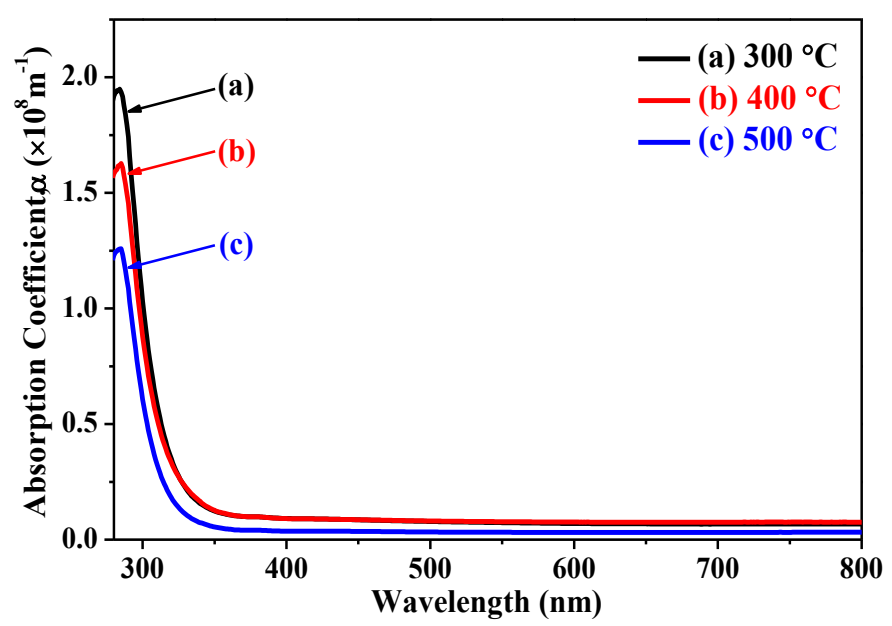

Fig. 4. The absorption coefficient of $\mathrm{NiO}$ thin films at different annealing temperatures.

It shows that the annealing temperature strongly affects the bandgap energies, as mentioned by Cayir [2]. From the result, the bandgap values slightly deviate from the reported values in literature, which were ranged between 3.6 to $4.0 \mathrm{eV}$. However, there a report explained the $\mathrm{NiO}$ bandgap was between 2.8 to $4.2 \mathrm{eV}$ [16]. The difference in current $E_{\mathrm{g}}$ may be due to the very thin film thickness below $60 \mathrm{~nm}$ for all samples. Besides, the increase in bandgap values of the $\mathrm{NiO}$ films when the annealing temperature is increased from $300{ }^{\circ} \mathrm{C}$ to $500{ }^{\circ} \mathrm{C}$ may be due to changes in the crystal structure [6]. The summary of the optical properties of $\mathrm{NiO}$ thin films annealed at different temperatures is shown in Table II. The variation in optical bandgap showed the impact of annealing temperature on the optical properties of the $\mathrm{NiO}$ films.

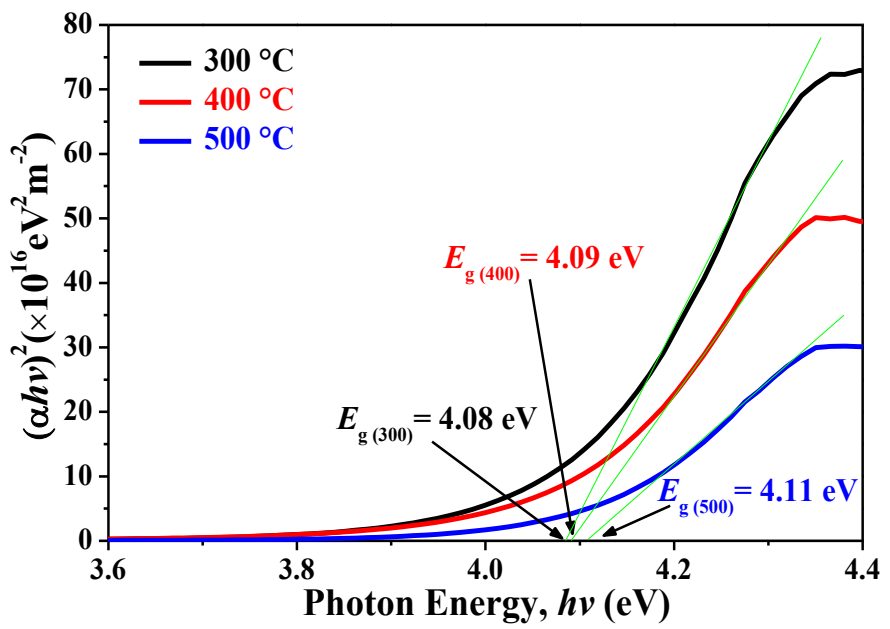

Fig. 5. Energy bandgap of NiO thin films estimated by Tauc's plot. 
TABLE II

THE TRANSMITTANCE AND OPTICAL BANDGAP OF NIO THIN FILMS AT DIFFERENT ANNEALING TEMPERATURES.

\begin{tabular}{ccc}
\hline $\begin{array}{c}\text { Sample } \\
\left({ }^{\circ} \mathbf{C}\right)\end{array}$ & $\begin{array}{c}\text { Transmittance, } \\
(\mathbf{\%})\end{array}$ & $\begin{array}{c}\text { Bandgap, } \\
\boldsymbol{E}_{\mathbf{g}} \\
(\mathbf{e V})\end{array}$ \\
\hline 300 & 76 & 4.08 \\
400 & 70 & 4.09 \\
500 & 83 & 4.11 \\
\hline
\end{tabular}

\section{Electrical Properties}

The current-voltage (I-V) measurement result using the $\mathrm{Ag}$ electrode in the voltage range between -10 to $10 \mathrm{~V}$ at room temperature is depicted in Fig. 6. It can be seen from the I-V plots, with the increase of supply voltage, the linear current is increased and exhibit ohmic behaviour. The values of resistance $(R)$, resistivity $(\rho)$, and conductivity $(\sigma)$ of the $\mathrm{NiO}$ thin films were calculated and summarized in Table III. It shows that the resistance value decreases as the annealing temperature is increased. The lowest resistance value is recorded for a $500{ }^{\circ} \mathrm{C}$-annealed sample with a value of 5.02 $\mathrm{M} \Omega$. The resistivity also decreases when the annealing temperature is increased. The resistivity values obtained in this study ranges between $4.52 \times 10^{-1}$ to $4.03 \times 10^{-1} \Omega \cdot \mathrm{cm}$. Besides, all $\mathrm{NiO}$ thin films have good conductivity at various annealing temperatures. The highest conductivity of $2.48{\mathrm{~S} . \mathrm{cm}^{-1}}^{-1}$ recorded at $500{ }^{\circ} \mathrm{C}$-annealed sample. The resistivity of $\mathrm{NiO}$ thin film was calculated from the gradient of the I-V measurement plot using the equation (4), while the conductivity is the inverse value of the resistivity.

$$
\rho=\left(\frac{V}{I}\right) \frac{A}{t}
$$

where $V, I, A$, and $t$ symbolize the voltage, current, surface area, and thickness, respectively. From the results, the resistance is found to be highly dependent on the annealing temperature, while the resistivity is dependent on the resistance, thickness of the thin film, and the surface area of the Ag electrode. According to Akinkuade et al. [5], the reduction in resistivity when the annealing temperature is increased is due to an increase in the grain size. This will lead to the reduction of grain boundaries and thus enhances carrier mobility. It is related to conductivity which represents the ability of the material to conduct electric current.

As reported by Ghougali et al. [15], the high electrical conductivity of the sample can be attributed to the high carrier concentration of the material. In addition, the good conductivity of the material also influences the good carrier mobility in the crystal structure. When the crystal structure of the film is near perfection, it will result in a reduced incidence of structural defects such as dislocations and grain boundaries. Increasing the quality of the crystals reduces the carrier scattering from structural defects, leading to higher mobility. In conclusion, the improved crystal quality reduces the carrier scattering from structural defects, thus contributing to higher mobility. From this explanation, it was in line with the results obtained in the XRD data for $500{ }^{\circ} \mathrm{C}$-annealed $\mathrm{NiO}$ films, where the better crystallinity is shown for this sample can be compared to the lower temperature-annealed samples.

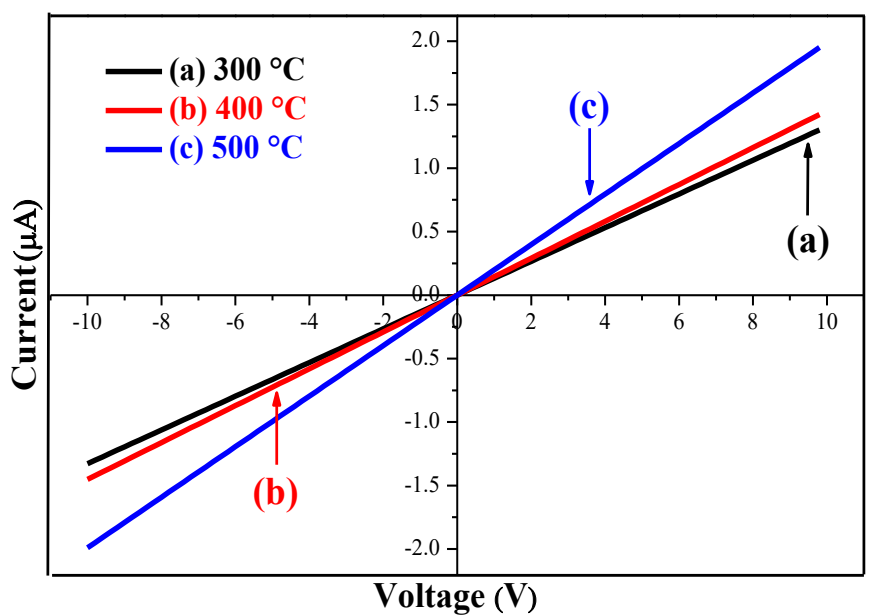

Fig. 6. I-V responses of $\mathrm{NiO}$ thin films at different annealing temperatures.

TABLE III

THE RESISTANCE, RESISTIVITY, AND CONDUCTIVITY VALUES OF NIO THIN FILMS

\begin{tabular}{|c|c|c|c|}
\hline $\begin{array}{c}\text { Sample } \\
\left({ }^{\circ} \mathrm{C}\right)\end{array}$ & $\begin{array}{c}\text { Resistance, } \\
R \\
(\mathrm{M} \Omega)\end{array}$ & $\begin{array}{c}\text { Resistivity, } \\
\boldsymbol{\rho} \\
\times 10^{-1}(\mathbf{\Omega} \cdot \mathbf{c m}) \\
\end{array}$ & $\begin{array}{c}\text { Conductivity, } \\
\sigma \\
\left(\mathrm{S.cm}^{-1}\right) \\
\end{array}$ \\
\hline 300 & 7.53 & 4.52 & 2.20 \\
\hline 400 & 6.89 & 4.49 & 2.23 \\
\hline 500 & 5.02 & 4.03 & 2.48 \\
\hline
\end{tabular}

\section{CONCLUSION}

A facile sol-gel spin coating method has been successfully employed to deposit $\mathrm{NiO}$ thin films on glass substrates at different annealing temperatures. From this study, it can be suggested that the $500{ }^{\circ} \mathrm{C}$-annealed thin film shows the best performance in terms of morphological, optical and electrical characteristics. The surface morphology analysis showed the growth of grains at high annealing temperature is favourable as agreed by XRD analysis. The XRD peak intensity of the deposited $\mathrm{NiO}$ thin films was enhanced by increasing the annealing temperature due to the improvement of the crystallinity of the films. All films have a cubic phase with a polycrystalline structure, with the most significant peak is at an annealing temperature of $500{ }^{\circ} \mathrm{C}$. The impact of annealing temperature on $\mathrm{NiO}$ thin films could also be characterized in optical properties, especially in the variation of bandgap energy values at different annealing temperatures. Besides, the optical characterization shows that all $\mathrm{NiO}$ thin films have high optical transparency. Finally, the $\mathrm{NiO}$ thin film produced increment in conductivity after the annealing process at a higher temperature. 


\section{AKNOWLEDGEMENT}

This research was funded by the REI grant (600-IRMI/REI $5 / 3$ (017/2018)). The authors thank the Faculty of Electrical Engineering (UiTM), Faculty of Engineering (UMS), and Ministry of Education (Higher Education), Malaysia for their contribution and support to this research.

\section{REFERENCES}

[1] M. S. Jamal, S. A. Shahahmadi, P. Chelvanathan, H. F. Alharbi, M. R. Karim, M. Ahmad Dar, M. Luqman, N. H. Alharthi, Y. S. Al-Harthi, M. Aminuzzaman, N. Asim, K. Sopian, S. K. Tiong, N. Amin, and M. Akhtaruzzaman, "Effects of growth temperature on the photovoltaic properties of RF sputtered undoped NiO thin films," Results in Physics, vol. 14, Art. no. 102360, 2019.

[2] T. Çayır Taşdemirci, "Influence of annealing on properties of SILAR deposited nickel oxide films," Vacuum, vol. 167, pp. 189-194, 2019.

[3] P. Yang, L. Li, S. Yu, H. Zheng, and W. Peng, "The annealing temperature and films thickness effect on the surface morphology, preferential orientation and dielectric property of $\mathrm{NiO}$ films," Applied Surface Science, vol. 493, pp. 396-403, 2019.

[4] A. Diha, S. Benramache, and B. Benhaoua, "Transparent nanostructured Co doped $\mathrm{NiO}$ thin films deposited by sol-gel technique," Optik, vol. 172, pp. 832-839, 2018.

[5] S. T. Akinkuade, W. E. Meyer, and J. M. Nel, "Effects of thermal treatment on structural, optical and electrical properties of $\mathrm{NiO}$ thin films," Physica B: Condensed Matter, vol. 575, Art. no. 411694, 2019.

[6] T. Chtouki, L. Soumahoro, B. Kulyk, H. Bougharraf, B. Kabouchi, H. Erguig, and B. Sahraoui, "Comparison of structural, morphological, linear and nonlinear optical properties of $\mathrm{NiO}$ thin films elaborated by SpinCoating and Spray Pyrolysis," Optik, vol. 128, pp. 8-113, 2017.

[7] D. R. Sahu, T.-J. Wu, S.-C. Wang, and J.-L. Huang, "Electrochromic behavior of $\mathrm{NiO}$ film prepared by e-beam evaporation," Journal of Science: Advanced Materials and Devices, vol. 2, pp. 225-232, 2017.

[8] S. D. Singh, A. Das, R. S. Ajimsha, M. N. Singh, A. Upadhyay, R. Kamparath, C. Mukherjee, P. Misra, S. K. Rai, A. K. Sinha, and T. Ganguli, "Studies on structural and optical properties of pulsed laser deposited $\mathrm{NiO}$ thin films under varying deposition parameters," Materials Science in Semiconductor Processing, vol. 66, pp. 186-190, 2017.

[9] I. Sta, M. Jlassi, M. Hajji, and H. Ezzaouia, "Structural, optical and electrical properties of undoped and $\mathrm{Li}$-doped $\mathrm{NiO}$ thin films prepared by sol-gel spin coating method," Thin Solid Films, vol. 555, pp. 131-137, 2014.

[10] N. Parimon, M. H. Mamat, M. K. Ahmad, I. B. Shameem Banu, and M. Rusop, "Highly Porous NiO Nanoflower-based Humidity Sensor Grown on Seedless Glass Substrate via One-Step Simplistic Immersion Method," International Journal of Engineering and Advanced Technology, vol. 9, no. 1, pp. 5718-5722, 2019.

[11] N. Parimon, M. H. Mamat, A. S. Ismail, I. B. Shameem Banu, M. K. Ahmad, A. B. Suriani, and M. Rusop, "Influence of annealing temperature on the sensitivity of nickel oxide nanosheet films in humidity sensing applications," Indonesian Journal of Electrical Engineering and Computer Science, vol. 18, no. 1, pp. 284-292, 2020.

[12] M. H. Mamat, N. Parimon, M. A. R. Abdullah, A. S. Ismail, M. F. Malek, W. R. W. Ahmad, A. S. Zoolfakar, A. B. Suriani, M. K. Ahmad, N. Nayan, I. B. Shameem Banu, R. Amiruddin, and M. Rusop, "Fabrication of Nickel Oxide Nanowall Network Films at Different Annealing Temperatures for Humidity Sensing Applications," International Journal of Engineering \& Technology, vol. 7, no. 4.18, pp. 277-282, 2018.

[13]M. Martínez-Gil, M. I. Pintor-Monroy, M. Cota-Leal, D. CabreraGerman, A. Garzon-Fontecha, M. A. Quevedo-López, and M. SoteloLerma, "Influence of annealing temperature on nickel oxide thin films grown by chemical bath deposition," Materials Science in Semiconductor Processing, vol. 72, pp. 37-45, 2017.

[14]Sahoo and R. Thangavel, "Effect of annealing temperature on physical properties of solution processed nickel oxide thin films," AIP Conference Proceedings, vol. 1961, pp. 030041-1-030041-5, 2018.

[15]M. Ghougali, O. Belahssen, and A. Chala, "Effect of Annealing in Physical Properties of NiO Nanostructure Thin Film," Journal of Nanoand Electronic Physics, vol. 9, no. 3, pp. 03043-1-03043-3, 2017.
[16]A. Yazdani, H. Zafarkish, and K. Rahimi, "The variation of E g -shape dependence of $\mathrm{NiO}$ nanoparticles by the variation of annealing temperature," Materials Science in Semiconductor Processing, vol. 74, pp. $225-231,2018$

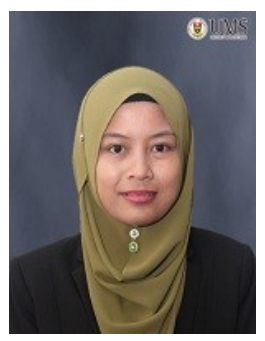

N. Parimon received her Bachelor and Master degrees in electrical \& electronic engineering, and electrical engineering, respectively from Universiti Teknologi Malaysia (UTM), Malaysia. She is a Lecturer at the Faculty of Engineering, Universiti Malaysia Sabah (UMS), Malaysia. She is currently pursuing her $\mathrm{PhD}$ at Universiti Teknologi MARA (UiTM), Malaysia where she is working on the fabrication of metal oxide-based humidity sensors.

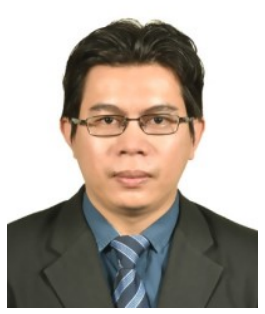

M. H. Mamat received his Bachelor degree in electrical \& electronic engineering and information engineering from Nagoya University, Japan and both of his $\mathrm{PhD}$ and Master degrees in electrical engineering from Universiti Teknologi MARA (UiTM), Malaysia. He is currently an associate professor at the Faculty of Electrical Engineering, UiTM. His research interests range over metal oxide semiconductors and nanodevices.

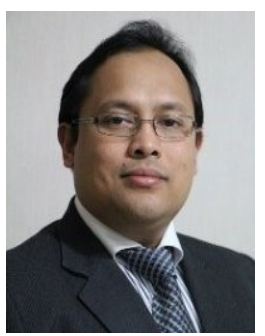

A. S. Zoolfakar received his Bachelor degree in engineering (electrical) with honours from Universiti Malaya (UM), Malaysia. He received his Master of Science (Engineering) in Microelectronic System and Telecommunications from The University of Liverpool, UK. He obtained his $\mathrm{PhD}$ at RMIT University, Australia. He is currently an associate professor at the Faculty of Electrical Engineering, Universiti Teknologi MARA (UiTM), Malaysia. His research interest focuses on transition metal oxides for sensor technology include aqueous chemical synthesis, vapour synthesis, solar cells, memristor, nanotechnology, and material sciences.

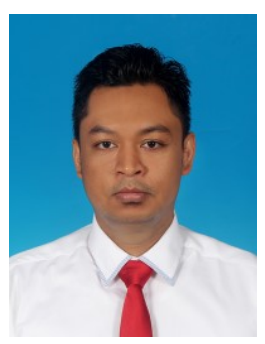

M. F. Malek received his Bachelor degree in Physics from Universiti Teknologi MARA (UiTM), Malaysia. He is also a research member of NANO-SciTech Centre (NST), Institute of Science (IOS), UiTM. He received both Master degree and $\mathrm{PhD}$ in electrical engineering from UiTM. He is currently a senior lecturer at the Faculty of Applied Sciences, UiTM. His focused research area is on nanotechnology, nanomaterials, and nanodevices. 


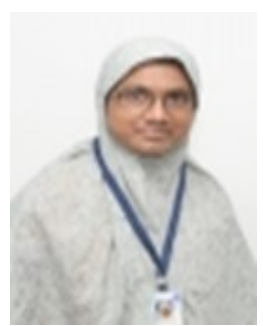

I. B. Shameem Banu received her first $\mathrm{PhD}$ in physics from Madurai Kamaraj University. She received her second $\mathrm{PhD}$ in condensed material physics from Anna University, Chennai, India. She is currently a professor at the Department of Physics, B.S. Abdur Rahman Crescent Institute of Science and Technology, Chennai, India.

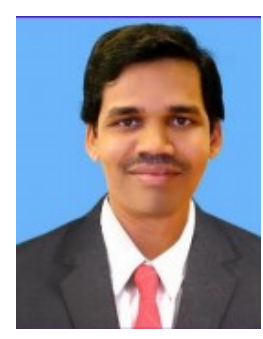

N. Vasimalai received his B.Sc and M.Sc in chemistry from Madurai Kamaraj University, Tamil Nadu, India. He received both M.Phil and $\mathrm{PhD}$ in Chemistry from Gandhigram Rural University, Tamil Nadu, India. He worked as Postdoctoral Fellow at National Cheng Kung University, Taiwan and Marie Curie Postdoctoral Fellow (Co-Fund) at International Iberian Nanotechnology Laboratory, Portugal. $\mathrm{He}$ is currently working as Assistant Pofessor at the Department of Chemistry, B.S. Abdur Rahman Crescent Institute of Science and Technology, Chennai, India. His field of specialization has been focused on the synthesis of fluorescent nanomaterials and their biosensor and biomedical applications.

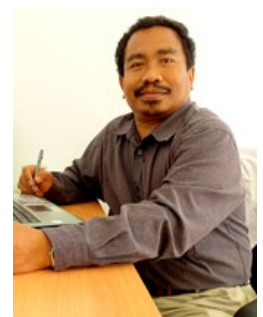

M. Rusop received his Bachelor in engineering from Nagoya University, Japan. He received his Master and $\mathrm{PhD}$ in engineering from Nagoya Institute of Technology, Japan. He is currently a professor at the Faculty of Electrical Engineering, Universiti Teknologi MARA (UiTM), Malaysia. 